\title{
Inspection of panel paintings beneath gilded finishes using terahertz time-domain
} imaging

Dandolo, Corinna Ludovica Koch; Cosentino, Antonino; Jepsen, Peter Uhd

Published in:

Studies in Conservation

Link to article, DOI:

$10.1179 / 0039363015 Z .000000000220$

Publication date:

2014

Document Version

Publisher's PDF, also known as Version of record

Link back to DTU Orbit

Citation (APA):

Dandolo, C. L. K., Cosentino, A., \& Jepsen, P. U. (2014). Inspection of panel paintings beneath gilded finishes using terahertz time-domain imaging. Studies in Conservation, 60(SUPPLEMENT 1), S159-S166.

https://doi.org/10.1179/0039363015Z.000000000220

\section{General rights}

Copyright and moral rights for the publications made accessible in the public portal are retained by the authors and/or other copyright owners and it is a condition of accessing publications that users recognise and abide by the legal requirements associated with these rights.

- Users may download and print one copy of any publication from the public portal for the purpose of private study or research.

- You may not further distribute the material or use it for any profit-making activity or commercial gain

- You may freely distribute the URL identifying the publication in the public portal 


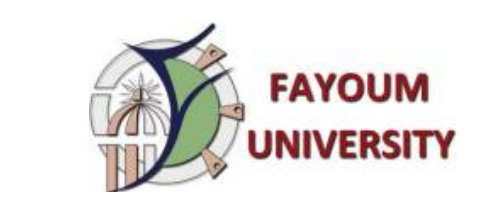

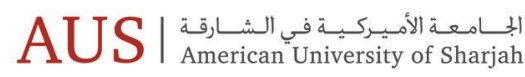

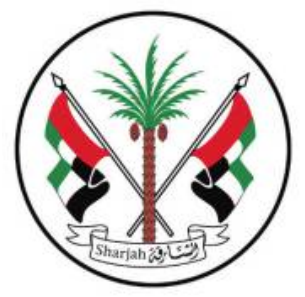

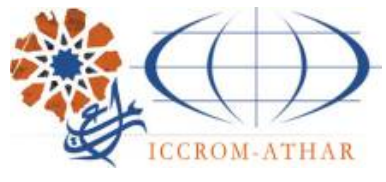

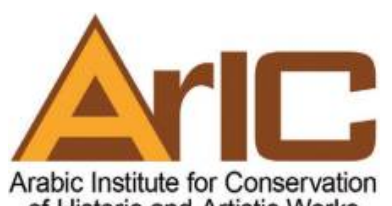
Arabic Institute for Conservation
of Historic and Artistic Works

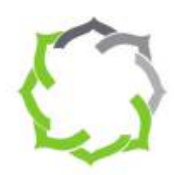

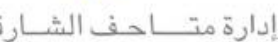

Sharjah Museums Department

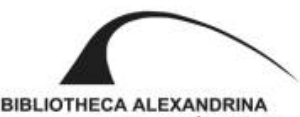

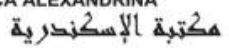

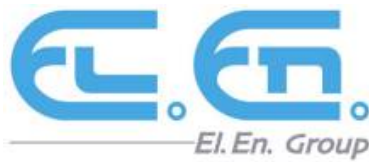

Laser Technologies

SWPecial

You can sign up for selected content free of charge, and also sign up for table of contents alerts at www.maneyonline.com/sic 


\title{
Inspection of panel paintings beneath gilded finishes using terahertz time-domain imaging
}

\section{Corinna L. Koch Dandoloㄹ, Antonino Cosentino², Peter Uhd Jepsen ${ }^{1}$}

\author{
${ }^{1}$ Department of Photonics Engineering, Technical University of Denmark, Denmark, ${ }^{2}$ Cultural Heritage Science \\ Open Source, Aci Sant'Antonio, Italy
}

\begin{abstract}
Scientific analysis of panel paintings could provide key information to art historians and conservators about the composition and condition of the constituent layers. Knowledge of the structure, stratigraphy, and condition of the subsurface layers of these objects is highly relevant to conservation measures, when stability problems such as delamination or internal cracking are considered. Terahertz time-domain imaging (THz-TDI) in reflection geometry is capable of highlighting interfaces between layers in a stratigraphic buildup, and thus makes structural information available in the form of subsurface 3D images and stratigraphic images (B-scans). The technique is contactless and non-invasive, and has been successfully applied to investigation of panel paintings. Regarding gilded panel paintings, the extremely high reflectivity of metals at submillimeter wavelengths generally precludes the transmission of electromagnetic waves through metallic films. Therefore, imaging of subsurface features below gilded finishes may be regarded as Very challenging. A small but non-negligible direct transmission through metal films occurs if the film thickness is of the order of the skin depth of the metal in the terahertz range, due to the skin effect. The thickness of gold leaf, a fraction of a micrometer, matches the skin depth of gold in the terahertz frequency range covered by THz-TDI devices. We therefore investigated and imaged subsurface features of panel paintings through gilded finishes with THz-TDI. Subsurface layers of three gilded panel paintings (two contemporary tempera panel replicas and one fourteenth-century icon) have been successfully imaged behind gold finishes with THz-TDI.
\end{abstract}

Keywords: Terahertz time domain imaging, Imaging techniques, Non-destructive characterization, Gilded panels, Panel paintings, Tempera panels Gold leafs gilded finishes

\section{Introduction \\ Panel paintings and gilded finishes in Europe: an overview}

Panels were used as supports in European painting from antiquity to the sixteenth century, when they were almost completely replaced by easel paintings on canvas. In the Byzantine world, panel paintings were largely in use before and after the iconoclastic periods (eighteenth and nineteenth centuries), while in Europe they were most prevalent in the thirteenth century. It is believed that this is related to the new liturgical practices of mass celebration introduced by the Fourth Council of the Lateran (1213), which saw the priest now faced ad orientem (East) and not versus populum, incentivizing the use of the altar as a frame for sacred images, and thus the production of altarpieces (Hill Stoner \& Rushfield, 2013). Given the widespread religious use of panel paintings, they

Correspondence to: Corinna L. Koch Dandolo, Department of Photonics Engineering, Technical University of Denmark, 2800 Kgs. Lyngby, Denmark. Email: clkd@fotonik.dtu.dk are often found to be adorned by gilded finishes. Gold was particularly appreciated in Christian sacred subjects for its mystical effect, the liturgical function, and for a purely devotional purpose: the high cost of the material was seen as an offering to the God (Trenti Antonelli, 2003).

Gilded finishes are not a Christian invention. Thin gold films were applied to objects with a decorative function more than six thousand years ago. The desired thickness of gold was obtained by artisans though different steps of gold thinning, such as hammering (the ancient process) or rolling (the modern process) to obtain foils, or beating to obtain leaves. The term foil is used when the gold film can be handled easily (i.e. several $\mu \mathrm{m}$ thick), and the term leaf is used when the gold film is so thin that it cannot sustain its own weight (i.e. $<1 \mu \mathrm{m}$ ). Gold foils were the first to be applied for decorative purposes, but rapidly the thickness of the foil was decreased, mostly to reduce costs. Decoration of sarcophagi by gold leaf less than $1 \mu \mathrm{m}$ thick is found in 
Egypt during the 3rd millennium BCE. Pliny the Elder (23-79 CE), in Naturalis Historiae, mentions that the gold artisans were able to obtain gold leaves less than $0.4 \mu \mathrm{m}$ thick (Darque-Ceretti \& Aucouturier, 2013). Gold can be beaten without any special difficulty to a thickness of about $0.1 \mu \mathrm{m}$.

\section{Terahertz time-domain imaging in reflection geometry: fundamentals}

Terahertz time-domain imaging (THz-TDI, also known as terahertz pulsed imaging) is a noninvasive, coherent imaging technique that can acquire inherently $3 \mathrm{D}$ data. $\mathrm{THz}$ radiation $\left(1 \mathrm{THz}=10^{12} \mathrm{~Hz}\right)$ lies between the millimeter and far-infrared regions of the electromagnetic spectrum. It is typically defined as the frequency range of $0.1-10 \mathrm{THz}(\sim 3-0.03 \mathrm{~mm}$ in wavelength, $\sim 3.33-333 \mathrm{~cm}^{-1}$ in wavenumber), but practical THz-TDI systems have a usable frequency range of approximately $0.1-4 \mathrm{THz}(\sim 3-0.07 \mathrm{~mm}$ in wavelength, $\sim 3.33-143 \mathrm{~cm}^{-1}$ in wavenumber). The attractive property of $\mathrm{THz}$ radiation is its ability to penetrate optically opaque and non-conducting materials.

For imaging applications, the source of contrast is the optical density of materials, and in reflection geometry the reflected $\mathrm{THz}$ signal is analyzed for reflections originating from the various interfaces present between the sample layers. Specifically, refractive index mismatches result in strong reflections from buried layers, and $\mathrm{THz}$ images are formed by the detection of absorption and refractive index changes, which in general occurs when there is a structural or material change in the sample under investigation. The recorded quantity in a THz-TD system is the electrical field strength of the detected electromagnetic pulse as a function of time (time-domain pulse or temporal waveform). In the majority of the systems in use, raster scanning of the $\mathrm{THz}$ beam across an object over two spatial dimensions $x-y$ is used for image formation, with a time-domain pulse recorded and subsequently processed at each spatial coordinate.

The temporal spacing between the reflections is proportional to the optical thickness of the layers, which means that the return time of the different parts of the reflected $\mathrm{THz}$ signal provides information about the penetration depth of the signal that is reflected, thereby enabling 3D time-of-flight (ToF) imaging. Bscans, or noninvasive cross-section images, are created by displaying the ToF (travel time) of the electric field as a function of $x-y$ linear position of the transceiver. Fourier transformation is used to convert the pulses from the time to the frequency domain, in principle allowing spectroscopic analysis.

$\mathrm{THz}$ images can be plotted utilizing different parameters. Using the time-domain data, images can be reconstructed from the measured data using the already-mentioned pulse delay with regard to a reference pulse (ToF). Plan-type images (C-scans) can be displayed using various parameters of the temporal pulse shape $E(t)$, such as the value of the electrical field at maximum, at minimum, or the difference between maximum and minimum, or calculated intensity over a specific time interval (time window) and centroid- or weighted peak-time. In the frequency domain, the spectral amplitude $E(\omega)$ at a specific frequency $\omega$ or in a frequency range is a meaningful quantity to plot, offering the possibility of identifying materials with special spectral absorption characteristics (Jackson et al., 2011).

\section{THz-TDI as an investigation tool for gilded panel paintings}

Scientific analysis of panel paintings could provide key information to art historians and conservators about composition and condition of the constituent layers, aiding in understanding of the artifact and in the development of appropriate conservation treatments. The knowledge of the inner structure, stratigraphy, and condition of the subsurface layers of these objects is highly relevant in conservation treatment when stability problems such as delamination or internal cracking have to be considered.

Compared to other standard imaging techniques commonly used for inspection, such as reflected infrared reflectography/photography or X-radiography, which provide 2D images, THz-TDI in reflection geometry is capable of highlighting individual interfaces between layers in the stratigraphic buildup, and it makes structural information available, providing both subsurface 3D images and stratigraphic images (B-scans). The technique is contactless and non-invasive, and it has been successfully applied for the investigation of panel paintings and other multilayered artworks (Fukunaga et al., 2010, 2011; Groves et al., 2009; Dandolo et al., 2013; Picollo et al., 2014). Here we are particularly interested in the use of THz-TDI for inspection of gilded panel paintings. The high reflectivity of metals at submillimeter wavelengths generally precludes the transmission of electromagnetic waves through metallic films, perhaps leading to the belief that the inspection of subsurface structures of panels covered by gilded finishes is impossible. However, a small but non-negligible direct transmission through metal films occurs if the film thickness is of the order of the skin depth of the metal in the $\mathrm{THz}$ range, due to the skin effect. The skin effect is a well-known electromagnetic effect which refers to the tendency of an alternating current to concentrate near the conductor surface within a very thin layer known as the skin depth. The value of the skin depth for electromagnetic waves in a metal is a frequency-dependent quantity determined 
by the penetration distance at which the electric field falls to $1 /$ e (Abul \& Weili, 2005; Kadlec et al., 2005; Laman \& Grischkowsky, 2008).

In the $\mathrm{THz}$ region, direct transmission through gold films of sub-micrometer thickness is consistent with a skin depth of $250 \mathrm{~nm}$ at $0.1 \mathrm{THz}$ and $80 \mathrm{~nm}$ at $1 \mathrm{THz}$ (Ordal et al., 1985; Abul \& Weili, 2005; Seo et al., 2009).

These penetration depths may match the thickness of thin gold leaf typically applied to panel paintings or other gilded artifacts, and thus some transmission can be expected. The complementary technique of $\mathrm{X}$-radiography, which is typically used for inspection of the internal structure of art artifacts, uses X-rays for transmission imaging. The absorption coefficient of gold at X-ray wavelengths is such that gold leaf is virtually invisible in radiography images, so that inspection of the gold leaf deposition itself is difficult. Thus, THz-TDI may be a versatile and unique technique to image subsurface features of panel paintings with gilded finishes.

\section{Materials and Methods}

\section{Analytical instrumentation and methodologies}

THz-TDI was performed with a commercial Picometrix T-Ray 4000 device, consisting of a femtosecond fiber laser coupled with $5 \mathrm{~m}$ long umbilical cords to a photoconductive $\mathrm{THz}$ transceiver head mounted on an $x-y$ scanning stage. The system utilizes a pump-probe-system for generating and detecting short pulses of electromagnetic radiation at $\mathrm{THz}$ frequencies. The frequency range covered by the device is approximately $0.05-2 \mathrm{THz}(\sim 6-0.15 \mathrm{~mm}$ in wavelength, $1.7-66 \mathrm{~cm}^{-1}$ in wavenumber). The signal-tonoise ratio (SNR) is about $80 \mathrm{~dB}$ at $0.5 \mathrm{THz}$. The frequency-dependent lateral resolution (or spatial resolution) of the system is better than $1000 \mu \mathrm{m}$, while the bandwidth-limited axial resolution (or depth resolution), which is related to the dielectric properties of the investigated materials, is in the order of $20 \mu \mathrm{m}$. The investigated artifacts have been scanned in $500 \mu \mathrm{m}$ steps, using a 320-picosecond (ps) measurement window, a time increment of 0.078 ps (detector time-resolution) and a reflection configuration at normal incidence.

\section{Panel paintings}

Data were acquired from two panel paintings replicas (no. 1 and no. 2) made by students of The Royal Danish Academy of Fine Arts, Copenhagen, Denmark, and on an original fourteenth-century icon.

Since we were interested in testing the capability of THz-TDI in imaging subsurface features behind gold finishes, the panels were raster-scanned from the front. If scanned from the back, the wooden panel would have attenuated the $\mathrm{THz}$ beam significantly, due to the high absorption of wood within the $\mathrm{THz}$ range, especially at atmospheric conditions, due to its the moisture content.

The fourteenth-century icon represents the Virgin with the Child and a Saint (Fig. 1) from the Public Library of Taormina, Sicily, Italy. The paint layer seems to be applied on a thin priming applied directly on the wooden support. The figures are depicted on a gold background. Gold was used to traces some details of the robes and aureoles. It is currently being treated at the Angelo Cristaudo conservation laboratory, Acireale, Sicily, Italy. Material losses were considerable, from the paint layers to the ground and wood panel. For this reason, the stratigraphy of the panel painting could be observed from the edges of the losses, leading the conservator to believe cross-sections to be unnecessary.

Panel painting no. 1 (Fig. 2A) faithfully reproduces the instructions in Cennino Cennini's treatise Il libro dell'Atre (The Book of Art), written at the beginning of the fifteenth century. The replica has a great value for evaluation of the THz-TDI technique since all the constituent layers were intentionally left exposed. Cloth was applied on the wooden support, and then covered by the priming (animal glue and gypsum). Ultramarine pigment was applied mixed with egg on a first drawing sketched in graphite pencil. A gilded layer made from gold leaf applied to a red bole, frames the pictorial scene.

Panel painting replica no. 2 (Fig. 3A) is also made on a wooden support covered by a priming over

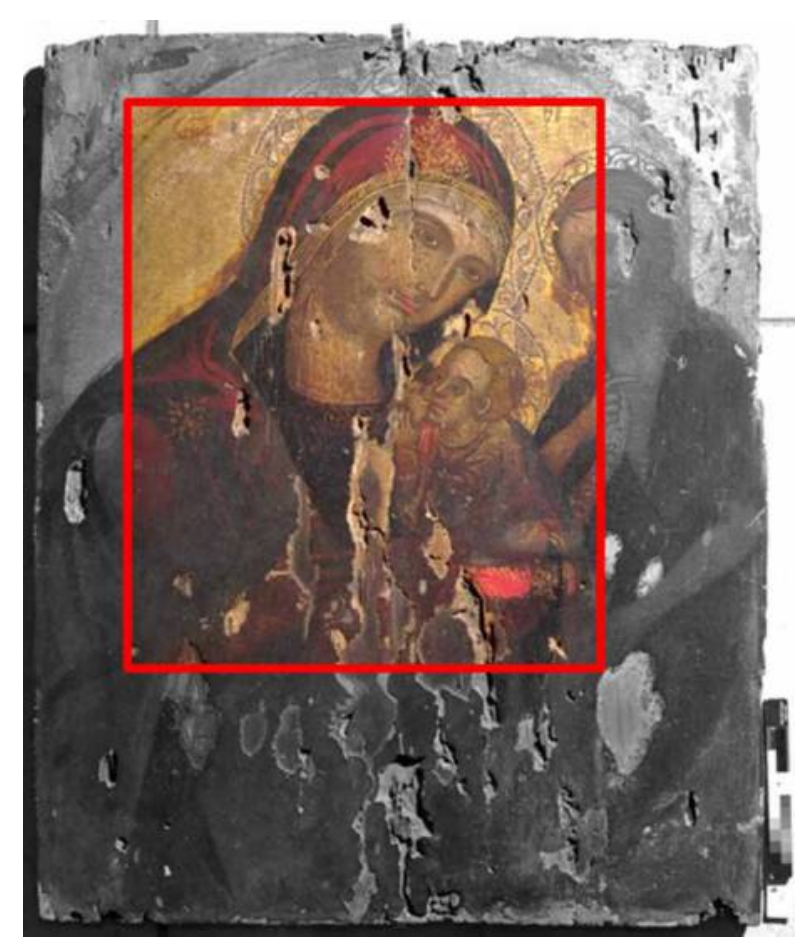

Figure 1 Fourteenth-century icon representing the Virgin with the Child and a Saint; the scanned area of the panel is represented in true colors. 


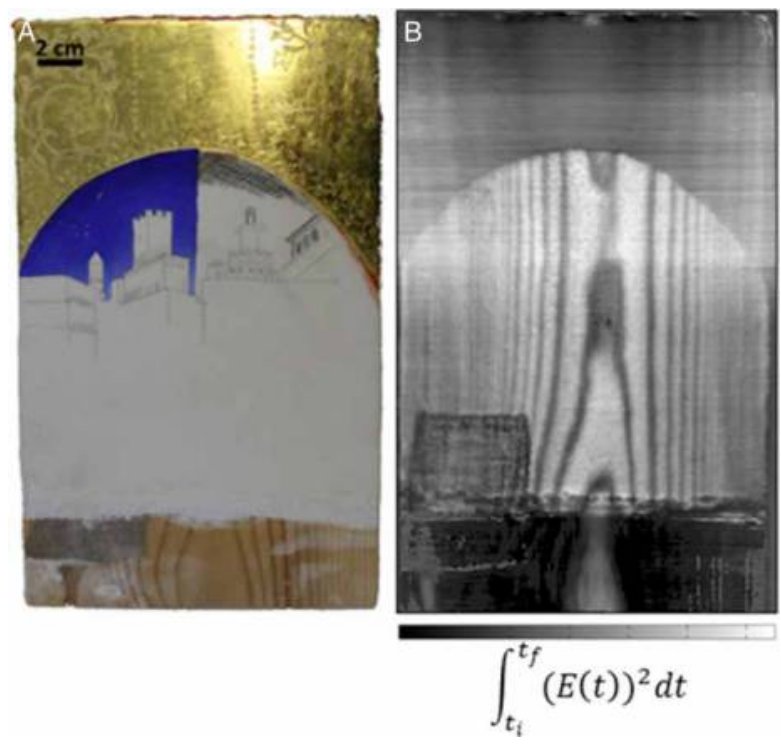

Figure 2 (A) Panel painting replica no. 1, visible image. (B) Panel painting replica no. 1, time-parametric $\mathrm{THz}$ image showing the location and extent of the cloth applied to the wooden panel and covered by the priming layer. The image varies from black to white for increasing valued of the integral of the power of signals recorded in the time interval between $t_{i}$ and $t_{f}$, where $E(t)$ in the color bar is the recorded temporal amplitude. The grain of the wood located behind the ground layer is visible, and also partially visible in the areas covered by the surface gilding.

which the gilding and the paint layer were applied. The pictorial scene is more complex, since gilding was used extensively together with paint to represent textiles. Incised lines in the gilding were used to represent geometrical and floral motifs. Even here the constituent layers were intentionally left exposed, so that the main stratigraphy of the panel was known, even without the use of cross-sections.

Decorative details made by scratching into the gold leaf with an awl or burin are present on all three panels.

\section{Results and discussion}

\section{Panel painting replicas}

Fig. 2A shows the visible image of panel painting replica no. 1, while Fig. 2B shows the THz time-parametric image, created by calculating the power of the electric signal associated with the pulses of interest, arising from reflections at the wood/plaster interface, including wood/cloth piece and cloth piece/plaster interfaces, where any are present. As can be seen in Fig. 2B, THz-TDI aids in identifying the location and extension of the cloth fragments applied directly to the wooden panel and covered by the priming. The grain of the wood located behind the priming is visible, also partially on the areas covered by the surface gilding, due to the skin effect in the gold film.

Fig. 3A shows the visible image of panel painting replica no. 2, while Figs. 3B-D show THz frequencyparametric images of the air/surface, paint/priming, and priming/wood interfaces, respectively. $\mathrm{THz}$ images were created by integrating the spectral amplitude over the full frequency range $(0.05-0.56 \mathrm{THz})$ after Fourier transformation of the single pulses of interest, isolated from the waveform by temporal windowing. THz-TDI gives information about the painting technique used for the panel, proving that the paint layer was applied to the gold background, which covers almost the total area of the priming, except for the parts delimitated by the dashed red line in Fig. 3B, where the paint layer has been applied directly to the priming. This was based on the lower reflectivity that these zones exhibit compared to the adjacent ones (appearing darker in the $\mathrm{THz}$ grayscale plan-type image), and highlighted by the B-scans (see Fig. 3E), which indicate that the strength of the pulses arising from the reflections at the subsurface interfaces are stronger compared to the uncovered areas, where no gilding is applied.

On the other hand, the strength of pulses arising from the reflections at subsurface interfaces in the gilded zones is high enough to be detected, and to enable the separation of single regions of interest from the whole temporal waveform by window function. The ToF plots of the individuated regions of interest (air/surface interface, paint/priming interface and priming/wood interface) are shown in Fig. 3G.

The incising in the gold surface appears darker in the $\mathrm{THz}$ image of the surface layer because of deflections of the incident beam caused by the irregularities (the incised lines themselves) at the surface. According to this, smoother gold areas appears whiter (i.e. have higher reflectivity) compared to the other areas.

$\mathrm{THz}$ gray-scale images of the subsurface layers, (paint/priming and priming/wood interfaces, shown in Fig. 3C and 3D, respectively) indicate that areas covered by surface gilding are darker compared to the uncovered ones, due to higher reflection at the surface metal film, which consequently reduces the direct transmission of radiation in depth.

The reading of the texture of the layers in these $\mathrm{THz}$ images is difficult because of their dark appearance, especially in the regions corresponding to the surface incising, where the detected beam is reduced significantly because of deflection of the reflected beam away from the normal direction. Despite this, a white spot (circled with red line in Fig. 3C) is visible in both the $\mathrm{THz}$ images of the subsurface layers. Inspection of the B-scans shows how this spot (circled with red line in Fig. 3E and zoomed in Fig. 3F) is located in the middle of the priming layer. For location, size and extension, and due to its high reflectivity value, the spot identified in the $\mathrm{THz}$ scan may be attributed to an air bubble inside the priming, quite commonly found in such layers. The internal defect has been localized in the interior of a 

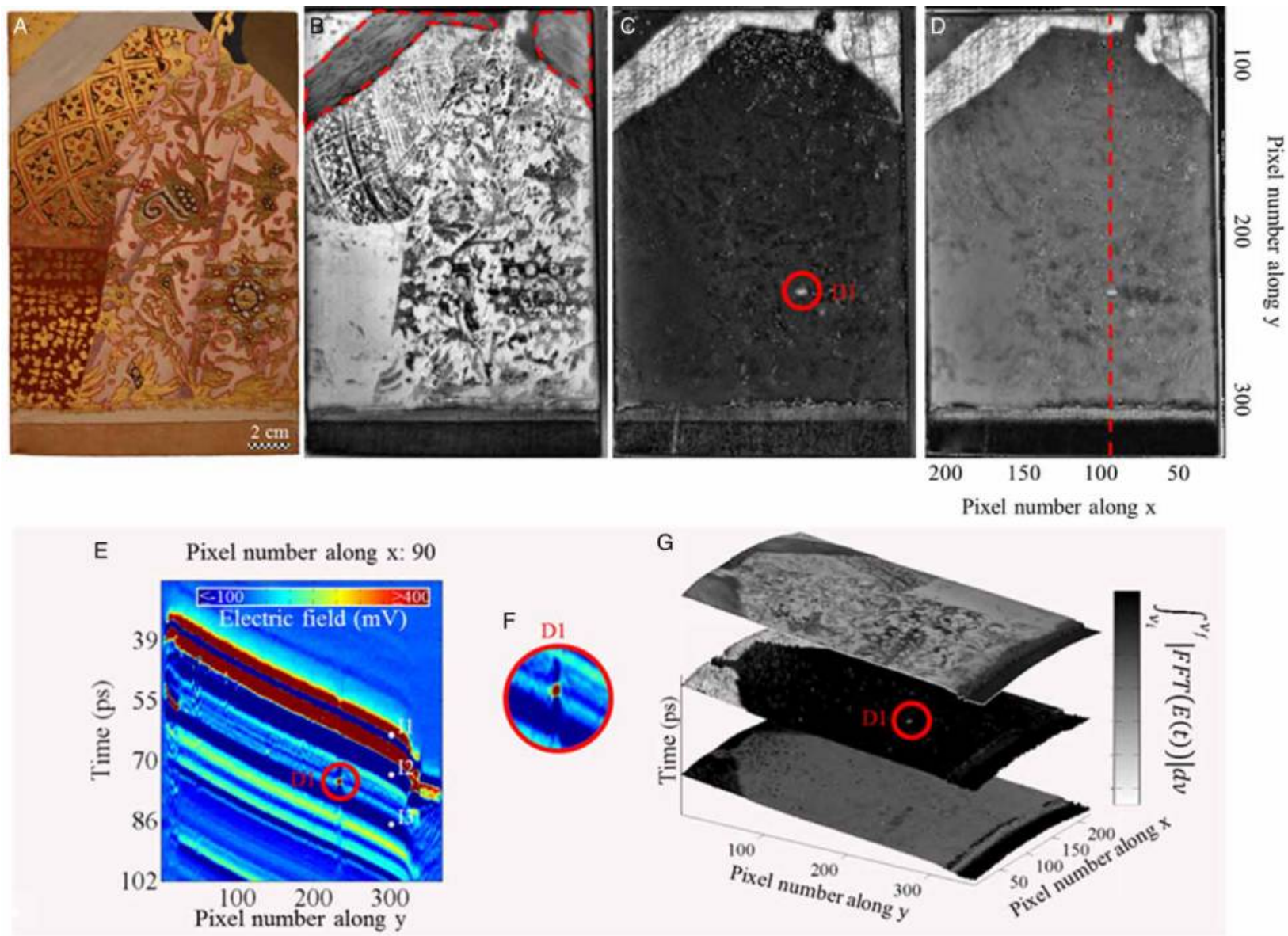

Figure 3 Visible, gray-scale THz C-scans and B-scan of panel painting replica no. 2. When used, the gray color map varies from black to white for increasing values of the spectral amplitude $(E(t)$ in the color bar) integrated within the frequency range $0.05-0.56 \mathrm{THz}\left(v_{i}-v_{f}\right.$ in the color bar) over time interval $(t)$ where the relevant peak is located. (A) Visible image. (B) Gray-scale frequency-parametric THz image of the air/surface interface. (C) Gray-scale frequency-parametric THz image of the paint/ priming interface. The red circle indicates the location of the anomaly (D1) (D) gray-scale frequency-parametric THz image of the priming/wood interface. (E) B-scan representing value (color map) and ToF (vertical axis) of the signal along the scan-line (horizontal axis) indicated by the red line of Fig. 3C); the three main interfaces (11-3) are found; the circled area indicates the location of a defect inside the plaster layer, compatible with an air bubble. (F) A zoom on the defect (D1) revealed by the B-scan of Fig. 3E). (G) ToF plots of the detected interfaces (from top to bottom: air/surface, paint /plaster, priming/wood interfaces).

layer located beneath the surface gilding, proving again the ability of $\mathrm{THz}$ radiation to penetrate thin gold leaf layers.

\section{The fourteenth-century icon}

The frequency-parametric THz image of the surface of the scanned area of the tempera panel is shown in Fig. 4B, and may be compared to the visible image (Fig. 4A). The image was created by integrating the spectral amplitude over the full frequency range after Fourier transformation of the pulse of interest, isolated from the temporal waveform by a window function. The high reflectivity of the metal in the $\mathrm{THz}$ range makes the background gold located under the paint layer clearly visible. At the contours of the faces of the figures, in the vicinity of the aureoles, it is possible to identify the straight edges of the applied gold leaf, evidence that leads us to assume that the artist used gold leaf for the gilded background. Thus, the THz-
TDI investigation immediately gives a substantial contribution in understanding the gilding technique.

Furthermore, THz-TDI facilitates the localization of the gilding used for tracing decorative motifs on the gowns (straight lines on the Child's garment and at the border of the Virgin's veil, floral motifs for the Virgin's mantle), not clearly perceptible in the visible image because of the intense brown of the surface varnish layer.

In addition, $\mathrm{THz}$ imaging contributes to understanding of the pigments used. The bright red highlights used on the Virgin's mantle and on her lips appear distinguishable in the $\mathrm{THz}$ image thanks to a reflectivity greater than that of adjacent pigments. It is well known that among the red pigments, cinnabar $(\mathrm{HgS})$ is characterized by high reflectivity within the $\mathrm{THz}$ range used, distinctive from other red pigments (NiCT, 2009). Thanks to the high reflectivity within the relevant $\mathrm{THz}$ range, the white pigments used for highlights on the faces, and to depict volume and 


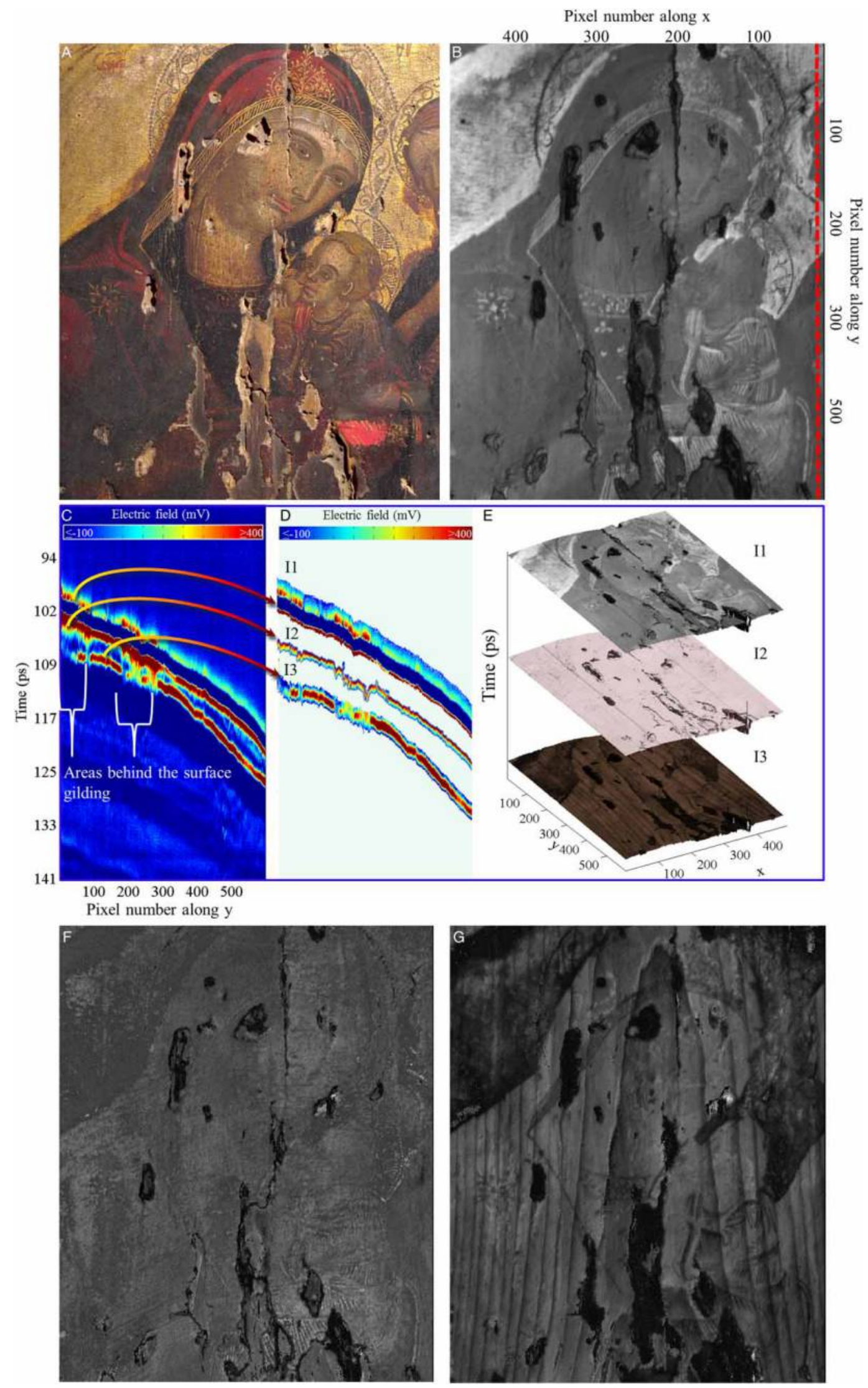

Figure 4 Visible, gray-scale THz C-scans, B-scan and ToF plots of the fourteenth-century icon. When not specified in the figures, monochromatic color maps vary from darker to lighter tonalities for increasing values of the spectral amplitude integrated within the frequency range $0.05-0.56 \mathrm{THz}$. (A) Visible image. (B) Gray scale frequency-parametric THz image of the air/ surface interface. (C) B-scan representing value and ToF of the signal along the scan-line indicated by the red line of Fig. 4B). (D) Single interfaces (air/surface, paint/priming, priming/wood) found, isolated from the B-scan of Fig. 4C). (E) ToF plots related to the three interfaces found (air/surface, paint/priming, priming/wood). (F) Gray-scale frequency-parametric THz image of the paint/priming interface. (G) Gray-scale frequency-parametric THz image of the priming/wood interface. 
features are clearly defined in the $\mathrm{THz}$ grayscale images, with their lighter tones of gray. Among white pigments contemporary to the painting, lead white $\left(\mathrm{Pb}_{3}\left(\mathrm{CO}_{3}\right)_{2}(\mathrm{OH})_{2}\right.$ or $\left.\mathrm{PbCO}_{3}\right)$ has the highest reflectivity in the $\mathrm{THz}$ range relevant here (Fukunaga, 2010; NICT, 2009), suggesting that this pigment was used. THz-TDI has enabled mapping of the distribution of surface pigments, localizing areas of interest for further non-invasive analysis, or suggesting sampling sites for chemical analysis of pigments (i.e. red areas of the Virgin's robe having a different $\mathrm{THz}$ response, and highlights on the faces).

Fig. 4C shows the column B-scan displaying the ToF of the electric field recorded along the scan-line drawn in Fig. 4B, with the 'colormap related to the strength of the recorded signals'. Accentuated by the chosen color-map (ranging from blue to red through cyan, yellow, and orange for increasing strength), it is clear that pulses arising from reflections at the paint/priming and priming/wood interfaces are strong enough to be detected on areas covered by the gilding located at the surface, even if the strength of the recorded electric field is lower than in the areas not covered by the gilding.

After isolating the detected interfaces (Fig. 4C), $\mathrm{THz}$ ToF plots were calculated (Fig. 4D) as well as $\mathrm{THz} \mathrm{C}$-scans of the interfaces between paint/priming and priming/wood (Fig. 4F-G). The texture of the subsurface interfaces, as appear in the corresponding plan-type images, can still be recorded for areas covered by the surface gilding, even if less clearly that for the uncovered ones.

\section{Conclusion}

We have shown that investigation of the subsurface features of gilded panel paintings and the characterization of their internal structure by means of THz-TDI in reflection geometry is possible, and, in particular, we have demonstrated that investigations behind gilding layers are also possible. Despite the very high reflectivity of metals at submillimeter wavelengths, a small but non-negligible direct transmission through gold leaf occurs if the gold leaf thickness is of the order of the skin depth of gold films in the $\mathrm{THz}$ range, due to the skin effect.

THz-TDI applied on the two panel painting replicas gave important information about the application technique.

For panel painting no. 1, THz-TDI identified the location and extent of the cloth fragments applied to the wooden panel and covered by the priming layer. The grain of the wood beneath the priming is visible in the $\mathrm{THz}$ image, and also partially in images of the areas covered by the surface gilding.

THz-TDI investigation of panel painting replica no. 2 proves that the paint layer was applied to the gold background, which covers almost the total area of the priming, except for small areas where the paint layer was applied directly on the priming. An internal defect, compatible with the presence of an air bubble inside the priming, was localized by imaging the subsurface interfaces, proving again the ability of $\mathrm{THz}$ radiation to penetrate thin gold leaf.

THz-TDI investigation of the fourteenth-century icon representing the Virgin with the Child and a Saint made a substantial contribution to understanding the gilding technique for the background. The square edges observed beneath behind the paint layers, only visible in the $\mathrm{THz}$ images, indicate the use of gold leaf. Furthermore, THz-TDI indicated gilding used for decorative motifs on the gowns (straight lines on the Child's garment and at the border of the Virgin veil's, and floral motifs of the Virgin's mantle), not clearly perceptible by inspection of the visible image owing to the intense brown surface varnish.

THz-TDI indicated the possible use of cinnabar for the red highlights used on the Virgin's mantle and lips, and lead white for the flesh tones. Thus, it provided mapping of the distribution of pigments on the surface, localizing areas of interest for further spot analysis.

The THz pulses arising from reflections at the subsurface paint/priming and priming/wood interfaces are strong enough to be detected even on areas covered by the surface gilding, allowing these interfaces to be imaged by $\mathrm{C}$-scans, and modeled by ToF plots.

We can conclude that the unique possibility of seeing through gilding layers while recording $3 \mathrm{D}$ information about the internal structure of an object makes THz-TDI is a very powerful technique which can complement X-ray-based examination techniques.

\section{Acknowledgements}

It is a pleasure to acknowledge with gratitude the financial support of Otto Mønsteds Fond for Lacona $\mathrm{X}$ conference attendance. We would like to acknowledge Mikkel Scharff, Head of Department and Associate Professor at the Royal Danish Academy of Fine Art, and Mads Christian Christiansen, Head of the Research, Analysis and Consultancy, Conservation Department, National Museum of Denmark, for having provided the tempera panel replicas investigated in this study. Special thanks go to the restorer Angelo Cristaudo for having provided access to the fourteenth-century gilded icon belonging to the Public Library of Taormina.

\section{References}

Abul, K.A. \& Weili, Z. 2005. Resonant Terahertz Transmission in Subwavelength Metallic Hole Arrays of Sub-Skin-Depth Thickness. Optics Letters, 30(21): 2945-2947.

Dandolo, C.L.K., Jepsen, P.U. \& Christensen, M. 2013. Characterization of European Lacquers by Terahertz ( $\mathrm{THz}$ ) Reflectometric Imaging. Marseille: IEEE. 
Darque-Ceretti, E. \& Aucouturier, M.C. 2013. Gilding for a Matter Decoration and Sublimation. A Brief History of the Artisanal Technical Know-How. International Journal of Conservation Science, 4(Special Issue): 647-660.

Fukunaga, K. \& Hosako, I. 2010. Innovative Non-invasive Analysis Techniques for Cultural Heritage using Terahertz Technology. Comptes Rendus Phvsique, 11(7): 519-526.

Fukunaga, K., Cortes, E., Cosentino, A., Stuenkel, I., Leona, M. Duling III, I.N. \& Mininberg, D.T. 2011. Investigating the Use of Terahertz Pulsed Time Domain Reflection Imaging for the Study of Fabric Layers of an Egyptian Mummy. Journal of the European Optical Society - Rapid Publications, 6.

Fukunaga, K., Hosako, I., Duling, I. N. \& Picollo, M. 2009 Terahertz Imaging Systems: A Non-Invasive Technique for the Analysis of Paintings. Munich, s.n.

Groves, R., Pradarutti, B., Kouloumpi, E., Osten, W. \& Notni, G. 2009. 2D and 3D Non-Destructive Evaluation of a Wooden Panel Painting Using Shearography and Terahertz Imaging. NDT\& E International, 42(6): $543-549$.

Jackson, J.B., Bowen, J., Walker, G., Labaune, J., Mourou, G., Menu, M. \& Fukunaga, K. 2011. A Survey of Terahertz Applications in Cultural Heritage Conservation Science.
IEEE Transactions on Terahertz Science and Technologv, 1(1): 220-231.

Kadlec, F., Kuzel, P. \& Coutaz, J.-L. 2005. Study on Terahertz Radiation Generated by Optical Rectification on Thin Gold Films. Optics Letters, 30(11): 1402-1404.

Laman, N. \& Griscchkowsky, D. 2008. Terahertz Conductivity of Thin Metal Films. Applied Physic letters, 93: 1-3.

NICT 2009. THz Spectral Database. [Online]. Available from: http ://thzdb.org. [Accessed 24 June 2014].

Ordal, M.A., Bell, R.J., Alexander Jr, R.W., Long, L.L., \& Querry, M.R., 1985. Optical Properties of Fourteen Metals in the Infrared and Far Infrared: $\mathrm{Al}, \mathrm{Co}, \mathrm{Cu}, \mathrm{Au}, \mathrm{Fe}, \mathrm{Pb}, \mathrm{Mo}, \mathrm{Ni}$, Pd, Pt, Ag, Ti, V, and W. Applied Optics, 24(24): 4493-4499.

Picollo, M., Fukunaga, K. \& Labaune, J. 2014. Obtaining Noninvasive Stratigraphic Details of Panel Paintings Using Terahertz Time Domain Spectroscopy Imaging System. Journal of Cultural Heritage, 16: 73-80.

Seo, M.A., Park, H.R., Koo, S.M., Park, D.J., Kang, J.H., Suwal, O.K. \& Kim, D.S. 2009. Terahertz Field Enhancement by a Metallic Nano Slit Operating Beyond the Skin-Depth Limit. Nature Photonics, 3(3): 152-156.

Stonor, J.H. \& Rushfield, R. 2013. Conservation of Easel Paintings. s.1.: Routledge.

Trenti Antonelli, M.G. 2003. La Pittura su Tavola. Livorno: Sillabe. 